\title{
UM RETRATO DA GUERRA E DO ESTADO DE EXCEÇÃO NO ROMANCE UM HOMEM: KLAUS KLUMP
}

Maria Isabel Bordini*

RESUMO: O presente artigo faz uma análise da figuração da guerra no romance Um homem: Klaus Klump, do escritor português Gonçalo M. Tavares. Partindo das considerações de Hannah Arendt sobre a violência e de Simone Weil a respeito da força, procura-se delinear como a guerra encontra nesse romance um tratamento ambivalente, sendo simultaneamente tomada como fenômeno da natureza, que foge ao controle da vontade e da razão, e como fenômeno histórico e especificamente humano, que manifesta a capacidade humana de inovar e modificar a natureza. Toma-se como eixo da análise a trajetória do personagem Klaus Klump sobre o qual a guerra tem um impacto revolucionário. Por fim sugere-se uma possibilidade de leitura para tal ambivalência considerando-se a guerra e o estado de exceção por ela instaurado como uma imagem para a dupla potencialidade que a transformação operada pelo ser humano sobre a natureza acarreta: por um lado, a construção de um mundo permanente e habitável; por outro, o exercício indiscriminado e destruidor da força e do domínio.

PALAVRAS-CHAVE: Guerra, Poder, Violência
* belbordini@gmail.com

Bacharel em Direito (UFPR) e em Letras Português (UFPR). Mestrado em andamento em Letras, Estudos Literários (UFPR).

ABSTRACT: For a while, I have been looking into the rosean writings for its tragicity. In this sense, the way Clément Rosset perceives silence in his book Logic of the Worst has revealed itself as an excellent theoretical resource to think about the silence in the wild inland. I have embraced the sense João Guimarães Rosa has given to the expression throughout his writings, i.e., for the writer, "the wild inland is the world". Thus, my analysis will start with a more general idea of silence, which is not segregated from life, especially the contemporaneous one, in its relationship with technique, to, at last, dedicate myself on what I intend to devise in the wild inland: the tragic silence.

KEYWORDS: War, Power, Violence 
1. Os títulos que compõem a tetralogia são: Um homem: Klaus Klump; A máquina de Joseph Walser; Jerusalém e Aprender a rezar na era da técnica.

2. Por exemplo, o protagonista e personagem-título de $A$ máquin de Joseph Walser aparece momentaneamente em Aprender a rezar na era da técnica: é um paciente que causa tumulto no hospital onde Lenz Buchmann, protagonista de Aprender a rezar, trabalha. Joseph Walser tem o dedo indicador direito amputado em decorrência de um acidente de trabalho - acidente que marcará sua trajetória de forma definitiva - e o médico Lenz Buchmann o repreende friamente pelo seu descontrole emocional, desdenhando-o em seguida: "Que importância tem um dedo? Um cobarde, pensou." TAVARES. Aprender a rezar na era da técnica, p. 50.

3. TAVARES. Um homem: Klaus Klump, p. 18.

4. TAVARES. Um homem: Klaus Klump, p. 19.

5. ARENDT, Hannah. Eichmann em Jerusalém - Um relato sobre a banalidade do mal.
O romance Um homem: Klaus Klump é o primeiro de uma tetralogia denominada $O$ Reino, do escritor português contemporâneo Gonçalo M. Tavares. Trata-se de uma série de quatro romances ${ }^{1}$ articulados não por uma linha de continuidade entre os enredos, que podem ser lidos de maneira independente uns dos outros, mas pelos temas, pelos cenários e pelas circunstâncias que as histórias apresentam em comum. As quatro narrativas se passam em uma mesma cidade não nomeada que sofre com a guerra. Há, portanto um conflito armado que está ou em desenvolvimento, ou em vias de acontecer, ou recém terminado em cada um dos romances. Dá-se a indicação de que se trata da mesma guerra que atravessa os quatro livros, uma vez que os enredos estão sutilmente interligados por meio de personagens e/ou elementos que fazem breves aparições (pequenas "pontas", por assim dizer) de um livro para outro ${ }^{2}$.

A guerra é, desse modo, um eixo temático que atravessa as quatro narrativas e lhes confere certa unidade. Em cada um dos romances em questão a guerra ocupa espaço diferenciado e recebe tratamento diverso. Ela constitui em todos eles, porém, um elemento-chave a partir do qual se desenvolvem as relações humanas aí retratadas. Ou seja, ela é um dado inolvidável para a análise dessas relações e, em alguns momentos, chega a ser mesmo o motor mais direto de muitas das ações dos personagens. No presente artigo procuraremos delinear possíveis significados para a guerra representada no primeiro dos romances de $O$ Reino.

Em Um homem: Klaus Klump, a guerra se desenvolve em seu percurso completo: início, enfrentamentos, ápice, declí nio e fim. Esse percurso nos é apresentado através do relato das transformações que o conflito bélico provoca na vida banal de um indivíduo banal: Klaus Klump, "um homem alto que tinha lido livros", "que detestava a ação, enojava-se com a terra" e "não apreciava de uma maneira particular a pátria”’. Proveniente de uma família rica, Klaus afasta-se dos pais ao decidir "editar livros contra a economia e a política do tempo"4. De início, o personagem adota uma posição de neutralidade diante da guerra que toma o seu país, mas tal postura será mantida apenas enquanto sua vida pessoa não for afetada. Ao caracterizar Klaus como um "indivíduo banal" que leva uma "vida banal", temos em mente aquilo que Hannah Arendt entende por "banalidade" no seu livro Eichmann em Jerusalém - Um relato sobre a banalidade do $\mathrm{mal}^{5}$. Vejamos de que modo esse conceito de banalidade pode ser útil para a análise do personagem Klaus Klump.

Em 1961, Hannah Arendt acompanhou e relatou, como correspondente da revista The New Yorker, o julgamento de Adolf Eichmann, oficial nazista que coordenou a logística de extermínio de milhões de pessoas, principalmente judeus, durante o Holocausto ${ }^{6}$. No livro resultante desse relato, que
6. Optei, neste trabalho, pelo uso do termo Holocausto ao invés de Shoá (calamidade, em í́diche) apenas por ser o primeiro mais amplamente conhecido que o segundo, apesar da inadequação semântica que aquele possa conter: do grego (óৗо́каuбтоv = ò $\lambda$ ov [todo] + kauotov [queimado]), a palavra Holocausto se refere aos sacrificios religiosos em que as vitimas (plantas, animais e ate seres humanos) oferecidas aos deuses eram queimadas completamente. Entendo que se possa considerar inadequado e potencialmente ofensivo referir-se ao massacre de judeus e outros grupos como um sacrifício à divindade, ainda mais sendo essa prática sacrificial uma característica da história religiosa das próprias vítimas do massacre. Contudo, permito-me ponderar que o uso corrente desse termo, para se referir ao massacre realizado pelo regime nazista, em geral não carrega intenção ofensiva e nem a consciência dessa inadequação semântica sendo estas as razões pelas quais optei por seguir utilizando o termo mais usual. No entanto, entendo que a questão é delicada e que o termo Shoá, apesar de menos usual, poderia fazer mais jus à memória. Assim, considero que é necessário ter em mente a história semântica do termo, bem como estar ciente da potencial inadequação ética e política de seu uso. No entanto, diante do seu emprego generalizado, penso que, em termos de conscientização e de ação política, mais útil do que envolver o termo em um do que linguístico, talvez seja tomar posse dele e ressignificá-lo em prol da manutenção da memória e da dignidade das vítimas do massacre ao qual o termo se refere. 
7. A incapacidade de pensar do ponto de vista de outra pessoa podemos assim considerar, compromete a capacidade de reflexão e de julgamento porque obscurece uma parte da realidade - e uma parte fundamental, dado que a pluralidade e a constituição dialógica do pensamento são dados inalienáveis da condição humana. Arendt relata que, tanto no interrogatório policial, quanto no julgamento que o sucedeu, Eichmann frequentemente se expressava por clichês, compondo o que os seus juízes disseram ser uma "conversa vazia". ARENDT. Eichmann em Jerusalém, p. 61. Sobre as origens dessa "conversa vazia", Arendt faz a seguinte análise, partindo da própria afirmação de Eichmann, "Minha língua é o oficialês": "Mas a questão é que o oficialês se transformou em sua única língua porque ele sempre fo genuinamente incapaz de pronunciar uma única frase que não fosse um clichê. (...) Sem dúvida, os juízes tinham razão quando disseram ao acusado que tudo o que dissera era 'conversa vazia' - só que eles pensaram que o vazio era fingido, e que o acusado queria encobrir outros pensamentos que, embora hediondos, não seriam vazios. (...) Quanto mais se ouvia Eichmann mais óbvio ficava que sua incapacidade de falar estava intimamente relacionada com sua incapacidade de pensar, ou seja, de pensar do ponto de vista de outra pessoa. Não era possível nenhuma comunicação com ele, não porque mentia, mas porque se cercava do mais confiável de todos os guarda-costas contra as palavras e a presença de outros, e portanto contra a realidade enquanto tal." ARENDT. Eichmann em Jerusalém, p. 61-62. combina jornalismo político com reflexão histórico-filosófica, Arendt cunha o famoso conceito de "banalidade do mal", através do qual analisa e expressa com acuidade o que foi, no seu entender, o fenômeno Eichmann, em particular, o fenômeno do Holocausto nazista, em geral: o resultado da combinação da capacidade destrutiva com a burocratização da vida pública. Isto é, Arendt não vê em Eichmann um monstro, um ser demoníaco, como os seus juízes o queriam retratar, mas um carreirista medíocre para quem o nazismo significou a oportunidade de "ser alguém". Um homem incapaz de pensar e de julgar por conta própria, porque incapaz de pensar do ponto de vista de outra pessoa ${ }^{7}$, é a conclusão de Arendt sobre o burocrata Eichmann. A aura de sistemática hipocrisia que constituía a atmosfera geral do Terceiro Reich teria contribuído para criar essa incapacidade, em Eichmann e em tantos outros. Pensando e se expressando por clichês, Eichmann definia-se como um respeitador das leis acima d tudo, o que na prática significou, para ele, a adesão irrestrita a Hitler, uma vez que, como o oficial mesmo explicou em julgamento, "as palavras do Führer tinham força de lei" Essa incapacidade de reflexão diante dos acontecimentos que o cercavam, bem como os atos criminosos dela resultantes, não são, contudo, de modo algum justificáveis e nem escusáveis de julgamento e punição. Pelo contrário: o apoio e obediência a uma política genocida, não importando quais sejam as motivações interiores (irreflexão, ambição ou ódio) de quem o realiza, implicam, segundo Arendt, uma responsabilidade objetiva. Quer dizer, a irreflexão de Eichmann e a banalidade do mal que ele cometeu (o mal foi, no seu caso, simples resultado da sua eficiência como burocrata do Terceiro Reich) possuem uma natureza política e devem ser considerados e julgados como tais. E política, diz Arendt, "não é um jardim-de-infância; em política, obediência e apoio são a mesma coisa."

A banalidade entendida como ausência de reflexão acerca dos próprios atos e das suas consequências, e entendida tam bém, por extensão, como a adesão a qualquer ordem social e/ ou legal sem a plena consciência de seu significado e de seus resultados políticos (para a comunidade humana em geral), encontra ecos na constituição e nas decisões do personagem Klaus Klump. Sua postura de neutralidade no início da guerra, seu subsequente engajamento em um grupo guerrilheiro por motivos de vingança pessoal e, por fim, sua adequação conformada à ordem social e econômica reestabelecida denotam a ausência de consciência quanto à repercussão coletiva de seus feitos, bem como um isolamento constitutivo do personagem. Após a guerra, ao assumir o papel de herdeiro e chefe dos negócios familiares que ele antes renegara, o personagem não se reintegra à sociedade enquanto indivíduo, mas enquanto função. Não há, portanto, um exercício consciente, livre e responsável da individualidade, mas
8. “Em Jerusalém, confrontado com provas documentais de sua extraordinária lealdade a Hitler e à ordem do Führer, Eichman tentou muitas vezes explicar que durante o Terceiro Reich as palavras do Führer tinham força de leil (Fuhrerworte haben Gesetzskraft), o que significava entre outras coisas, que uma ordem vinda diretamente de Hitler náo precisava ser escrita." (Grifo nosso.) ARENDT. EIChmann em Jerusalém, p. 165

9. ARENDT. Eichmann em Jerusalem - Um relato sobre a banalidade do mal p. 302.

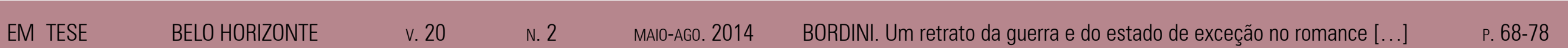


apenas obediência a uma ordem exterior. E esse tipo de postura encontra-se na base da atitude burocrática e legalmente conformada que Arendt associou à banalidade do mal.

O isolamento, isto é, a retirada por parte do indivíduo da esfera pública, âmbito onde os interesses coletivos são discutidos e onde a reflexão e a liberdade se fazem fundamentais, é outra postura que se encontra na base do mal banal. Essa postura marca fundamentalmente a trajetória de Klaus Klump. Há uma linha de continuidade entre o isolamento intelectual do Klaus editor de livros antes da guerra o isolamento entre o grupo de guerrilheiros na floresta, o isolamento na delinquência dentro do sistema prisional e o isolamento na existência individual de Klaus enquanto negociante bem-sucedido depois da guerra. Esse isolamento, embora já fosse um traço comportamental do personagem no período anterior à guerra, parece ter sido potencializado por esse evento. Nesse sentido, analisemos mais pormenorizadamente a dinâmica da guerra neste romance.

O primeiro capítulo de Um homem: Klaus Klump traz uma descrição breve e entrecortada do início da guerra, marcada pela entrada dos tanques inimigos na cidade. Joga-se a com a oposição e a aproximação entre natureza e humanidade. A frase de abertura do romance diz: "a bandeira de um país é um helicóptero: é necessário gasolina para manter a bandeira no ar"10. Essa formulação introduz a ideia de que a organização humana (no caso, um país) é um construto, uma criação, algo que difere, portanto, da natureza, cujos elementos estão dados, não são construídos ou fabricados. $O$ narrador, a seguir, enuncia: "Avançamos sobre a geografia, estamos ainda no sítio antes da geografia, na pré-geografia Depois da História não há geografia."11

A História é composta pelo conjunto das ações humanas e, nesse sentido, é o processo de transformação da matéria (da natureza) e de criação do mundo, entendendo-se o mundo aqui enquanto produto das mãos humanas, do trabalho (no sentido em que Hannah Arendt o entende ${ }^{12}$ ). A História permanece, a geografia, como dado físico e material, lhe cede lugar. A consideração seguinte do narrador insere a guerra no processo histórico de criação do mundo e aproxima, colocando em paralelo, duas atividades humanas distintas: a ação violenta (a guerra), por um lado, e a ação criadora, o fazer (a escultura), por outro. O narrador diz: "O país está inacabado como uma escultura: vê a geografia de um país: falta-lhe terreno, escultura inacabada: invade o país vizinho para finalizares a escultura. Guerreiro-escultor"13. Portanto, de início a guerra recebe, no romance, a marca do fazer - é algo que se faz, que se constrói como uma escultura -, ou seja, a marca do humano em oposição ao natural. A marca do histórico.

Sucedem-se então flashes de cenas que apresentam a guerra tomando conta da cidade: as notícias correm ("Alguém
11. TAVARES. Um homem: Klaus Klump, p. 7.

12. "O trabalho produz um mundo 'artificial' de coisas, nitidamente diferente de qualquer ambiente natural. Dentro de suas fronteiras habita cada vida individual, embora esse mundo se destine a sobreviver e a transcender todas as vidas individuais. A condição humana do trabalho e a mundanidade." ARENDT. A condição humana, p. 15. Ver também pp. 149 e seguintes.

13. TAVARES. Um homem: Klaus Klump, p. 7.
0. TAVARES. Um homem: Klaus Klump, p. 7.
EM TESE

BELO HORIZONTE

v. 20

N. 2

MAIO-AGO. 2014

BORDINI. Um retrato da guerra e do estado de exceção no romance [...]

P. $68-78$ 
14. TAVARES. Um homem: Klaus Klump, p. 8.

15. TAVARES. Um homem: Klaus Klump, p. 9.

16. TAVARES. Um homem: Klaus Klump, p. 9.

17. TAVARES. Um homem: Klaus Klump, p. 11.

18. TAVARES. Um homem: Klaus Klump, p.11.

19. TAVARES. Um homem: Klaus Klump, p. 12. furiosamente na rua tentava vender os jornais. Os tanques entravam na cidade, as notícias aceleravam no papel"14); o medo se alastra, especialmente entre os mais vulneráveis, como as mulheres ("Johana urina-se pelas calças. Urinei-me, diz ela Desculpa." ${ }^{15}$ ); as mulheres são invadidas pelos soldados, como uma extensão da invasão da cidade ("Os homens que são mais fortes entram para o exército, os homens que são mais fortes violam as mulheres que ficaram atrás, mulheres dos inimigos que fugiram." $\left.{ }^{16}\right)$; e, por fim, instala-se um novo poder na cidade, que submete a humilhações os homens assim dominados ("Ontem haviam ameaçado partir os óculos a Klaus. Klaus ajoelhou-se: beijou as botas de um homem. ${ }^{17}$ ).

A sucessão dessas cenas, especialmente a última, a da humilhação, parece conduzir a uma mudança súbita na caracterização da guerra, antes tida como uma modalidade do fazer humano: a guerra passará então a ser explicada pela lógica da natureza, uma lógica que não comporta a vergonha. Lê-se, por exemplo: "Klaus não se tinha envergonhado enquanto dava um beijo na bota direita do soldado. (...) Porque quando se tem medo não se tem vergonha, ou a vergonha ocupa menos espaço que o medo enorme." ${ }^{18} \mathrm{E}$ ainda: "A vergonha não existe na natureza. Os animais sabem a lei: a força, a força; a força." ${ }^{19}$ Ademais, segundo a lógica da natureza, a guerra tampouco comporta a injustiça: "Não há animais injustos, não sejas imbecil. Não há inundações injustas ou desabamentos da maldade. A injustiça não faz parte dos elementos da natureza." 20

Essa analogia entre a violência humana da guerra (antes entendida como um fazer, como um ato especificamente humano e histórico) e a força enquanto lei da natureza gera uma quebra de expectativa no leitor, um pequeno choque, em relação ao que fora enunciado anteriormente. Essa quebra de expectativa produz o efeito de mergulho súbito num universo cujas regras de funcionamento não estão claras e onde as relações humanas possuem uma dinâmica imprecisa, uma dinâmica, por assim dizer, metade homem, metade animal. Introduz-se, desse modo, a especificidade da guerra tal como figurada nos romances de Tavares: trata-se de um fenômeno de caráter híbrido, na fronteira entre o humano e o natural.

Como fenômeno híbrido, a guerra instaura o seguinte conflito: ela carrega, por um lado, a potencialidade de destruição daquilo que nos caracteriza como humanos - pois ameaça, dentre outras coisas, destruir o mundo material onde e através do qual nos relacionamos e nos tornamos propriamente humanos -, e, por outro, ela expõe aspectos da condição humana que não se revelariam em outro contexto, apresentando, desse modo, uma face potencial e paradoxalmente humanizadora. Aliás, esse conflito parece ter sido percebido por Simone Weil em seu ensaio "A Iliada ou
20. TAVARES. Um homem: Klaus Klump, p. 12.

EM TESE

BELO HORIZONTE

v. 20

N. 2

MAIO-AGO. 2014

BORDINI. Um retrato da guerra e do estado de exceção no romance [...]

ค. $68-78$ 
21. WEIL. A llíada ou o poema da força, pp. 319-344.

22. WEIL. A llíada ou o poema da força, p. 324.

23. WEIL. A llíada ou o poema da força, p. 325.

24. WEIL. A llíada ou o poema da força, p. 325.

25. Simone Weil diz que a força contém o poder de transformar um homem em coisa, em cadáver, e que desse poder "procede um outro poder prodigioso sob uma outra forma - o de transformar em coisa um homem que continua vivo", condição de que padecem, no contexto da llíada e do mundo antigo em geral, os homens e mulheres que são transformados em escravos. WEIL. A llíada ou o poema da força, p. 320 . o poema da força” ${ }^{21}$, em que a filósofa propõe como questão central da Ilíada a sujeição de todos, perdedores e vencedores, à força.

Simone Weil entende a força como uma potência que reifica, que transforma em coisa tanto aqueles que a exercem quanto aqueles que a sofrem. "Tal é o domínio da força", diz ela, "domínio que vai tão longe quanto o da natureza."22 Os que a exercem são "coisificados" tanto quanto aqueles que a sofrem porque se trata de "um domínio tão frio, tão duro como se fosse exercido pela matéria inerte." ${ }^{23}$ Desse modo, a guerra enquanto exercício da força seria, na Iliada, um processo que transforma a todos, sem exceção, em coisas, em não-humanos. Diz Weil:

Com a mesma dureza com que a força esmaga os vencidos, embriaga aquele que a possui ou julga possuí-la. Ninguém a possui verdadeiramente. Os homens não estão divididos, na Iliada, em vencidos, em escravos, em suplicantes de um lado e, do outro, em vencedores, em chefes; não há um só homem que não seja obrigado em algum momento a curvar-se sob a força. ${ }^{24}$

A autora indica, com isso, que a guerra é uma realidade humana que desumaniza todos os que nela se envolvem ${ }^{25}$. No entanto, a filósofa ao mesmo tempo aponta para o fato de justamente essa realidade nos dar a percepção da radical igualdade que caracteriza a condição humana:
Assim a violência esmaga aqueles que toca. Acaba por aparecer como exterior tanto ao que a maneja quanto ao que sofre com ela; nasce, então, a ideia de um destino sob o qual algozes e vítimas sejam igualmente inocentes, os vencedores e os vencidos irmãos na mesma miséria. O vencido é uma causa de infelicidade para o vencedor, como o vencedor para o vencido. ${ }^{26}$

Para Weil, o tema central da Ilíada seria a amargura resultante da "subordinação da alma humana à força" 27 , subordinação que acomete tanto vencedores quanto perdedores ${ }^{28}$. Ao mesmo tempo, a filósofa sugere que a compreensão dessa subordinação universal pode conduzir a uma humanização das relações a partir da percepção da miséria humana comum: "Só é possível amar e ser justo quando se conhece o poder da força e quando se sabe não respeitá-lo" ${ }^{\text {”29 }}$, diz.

Isso parece ir ao encontro da proposta de um hibridismo ou de uma indeterminação da natureza da guerra que se encontra nos romances de Tavares, nos quais ora a guerra é fenômeno que segue a lógica da natureza e da pura força, destruindo aquilo que nos torna humanos; ora é uma realização humana da mesma ordem que a construção de uma escultura ou monumento, sendo, portanto, um índice de humanidade e não de coisificação.

Em Um homem: Klaus Klump, a guerra é, como vimos, a partir de certo ponto apresentada como regida pela lei da
26. WEIL A llíada ou o poema da força, p. 331.

27. "A amargura cai sobre a única causa justa de amargura, a subordinação da alma humana à força, isto é, afinal de contas: poema da força, p. 341

28. “O poder que ela [a força] possui de transformar os homens em coisas e duplo, e se exerce no sentido de ambos os lados; petrifica diferentemente, mas igualmente, as almas dos que a sofrem e dos que a manejam." WEIL. A llíada ou o poema da força, p. 336

29. WEIL. A llíada ou o poema da força, p. 342.

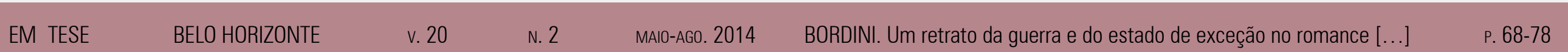


30. TAVARES. Um homem: Klaus Klump, p. 12-13. natureza, a lei da força, sem deixar de ser, ao mesmo tempo, um construto humano. A dissonância desse quadro parece provir da naturalização da violência humana. $\mathrm{O}$ narrador enuncia tal naturalização, mas não a desmascara ou julga, apenas a formula, e não parece ter qualquer posicionamento moral diante das coisas que relata, na maior parte das vezes, com uma crueza que pode ser confundida com cinismo. Assim, lê-se no romance:

Os homens quiseram introduzir na Natureza coisas inventadas pelos fracos: foram os fracos que inventaram a injustiça para mais tarde poderem inventar a compaixão. Nem a água dócil percebe o que é isso de injustiça. Queres ser mais bondoso que uma substância química que se escreve tão simplesmente como isto: $\mathrm{H}^{2} \mathrm{O}$ ? Não sejas imbecil: olha para os tanques: dispara com eles, ou contra eles. A vida em guerra só tem dois sentidos: com eles ou contra eles. Se não queres morrer beija as botas do mais forte, é isto. ${ }^{30}$

O trecho acima denota, como apontamos, uma redução da existência humana à lógica da natureza, isto é, à lógica da prevalência do mais forte. No entanto, a violência humana não é, ou não é apenas, um dado da natureza. Pois ela implica a existência de uma comunidade política (dá-se sempre entre seres humanos, e qualquer associação de seres humanos cria uma comunidade política). Por conta disso, a violência humana não pode ser um simples exercício da força, se entendermos que a força é uma potência "cega" da natureza, mas sim um exercício instrumentalizado da força, ou seja, uma utilização da força visando a um determinado fim (conquista de um território, dominação de um grupo ou povo, ou eliminação deste etc.), visto que os seres humanos, diferentemente da natureza, procuram agir teleologicamente. Uma possível forma de leitura da figuração da guerra em Um homem: Klaus Klump (e em toda a tetralogia O Reino, pode-se pensar) consiste em perseguir o significado e as consequências dessa dissonância resultante da equiparação da guerra a um fenômeno da natureza.

Em dado momento, ao tentar classificar os sons da guerra buscando entender se seriam sons animais ou humanos - ou uma mistura dos dois, tais como os sons que suas amantes produziam no ato sexual -, Klaus Klump conclui que os sons da guerra não se restringem a nenhuma das duas coisas. São sons de outra ordem, porque consistem em repetições exatas que nem o homem, nem a natureza são capazes de executar. Neles Klaus acredita estar anunciado "o início de uma nova força que em breve iria conquistar a terra" ${ }^{31}$. Lê-se no romance:

Que sons, afinal, eram aqueles - o da bala, o do gatilho a ser preparado, o da granada? O de um certo som preto - ele não conseguia encontrar uma melhor definição - som preto que
31. TAVARES. Um homem: Klaus Klump, p. 88.

EM TESE

\begin{abstract}
BELO HORIZONTE
\end{abstract}
v. 20

N. 2

MAIO-AG0. 2014

BORDINI. Um retrato da guerra e do estado de exceção no romance [...]

P. $68-78$ 
32. TAVARES. Um homem: Klaus Klump, p. 86-87.

33. TAVARES. Um homem: Klaus Klump, p. 88. ele ouvia sair dos sítios onde uma bomba havia rebentado há segundos - que sons eram esses?

(...)

Mas que som era aquele que saía das máquinas, se não era o do disforme da natureza nem uma frase. E se não era nem de perto nem de longe semelhante à mistura animal-homem dos gemidos das amantes de que Klaus se recordava. Seriam então esses sons o que alguns designaram, durante a História, como sons místicos, sons que não são dos homens nem da terra? ${ }^{32}$

Essa passagem se comunica com as proposições iniciais do romance, com o jogo de aproximação entre a lógica da guerra e a lógica da natureza. Depois de ter tido uma experiência pessoal da guerra, Klaus parece obter uma resposta para a dissonância decorrente dessa aproximação: a guerra não é nem um fenômeno da ordem da natureza, nem um fenômeno dos homens (a parte mais inteligente da natureza segundo Klaus), mas uma terceira coisa, pela qual Klaus se encontra fascinado:

Nem o som das frases dos livros, nem o som de coisas naturais a baterem em outras coisas naturais, nem estes dois sons misturados no acto da física amorosa: a cabeça de Klaus estava agora fascinada pelo som, quase estúpido, quase sem história, da bala e da bomba. O som que anunciava um novo Deus. ${ }^{33}$
A guerra é, portanto, algo que se impõe, "um novo Deus". Escapa à atuação individual e não parece ser simplesmente um fazer, um produto do trabalho humano, pois possui um funcionamento autônomo. Tudo o que cabe aos indivíduos parece ser procurar formas de sobreviver em meio dela. Podese dizer que Um homem: Klaus Klump é um romance sobre como agem os indivíduos quando a guerra instaura o estado de exceção, um estado de suspensão dos direitos e garantias individuais assegurados por uma ordem constitucional democrática, ou, de forma mais ampla, por qualquer conjunto de regras que se encontre na base de uma comunidade humana. A falência ou a suspensão dessa ordem abre espaço para uma zona cinzenta entre o humano e o animal na qual a sedução de uma ordem supra-humana, que absorva e dispense a capacidade humana de autodeterminação, bem como a relevância da atuação individual, pronunciadamente se instala.

Mas não se trata apenas disso: um romance sobre o estado de exceção. Pois, como mencionado acima, a não univocidade que transparece no romance acerca da natureza da guerra permite pensar que se trata simultaneamente de algo mais geral: o embate entre a caoticidade da natureza e a tentativa de organização do mundo constantemente empreendida pelo ser humano. E também, decorrente disso, a concomitante coisificação e redenção do gênero humano que a força parece acarretar, segundo a análise de Simone 
34. Segundo Simone Weil a sujeição à força é inevitável para todos na llíada, mas ao mesmo tempo se sugere que essa subordinação è o que possibilita a valorização das realidades humanas que escapam à materialidade: "A amargura cai sobre a única causa justa de amargura, a subordinação da alma humana à força, isto é, afinal de contas: à matéria. Essa subordinação a mesma em todos os mortais, embora a alma a suporte de diversas maneiras, conforme grau de virtude. Ninguém, na llíada, Ihe escapa, assim como ninguém neste mundo pode escapar-Ihe. Nenhum dos que sucumbem a ela é olhado por isso como desprezível. Tudo o que, no interior da alma $e$ nas relações humanas, foge ao império da força, é amado, mas amado dolorosamente, por causa do perigo de destruicãa continuamente pendente." (Grifo continuamente pendente." (GifC poss.) WELL. A Illada ou O

35. “(...) o sentimento da miséria humana é uma condição da justiça e do amor. Quem ignora até que ponto a fortuna variável a necessidade mantêm toda alma humana sob sua dependência não pode olhar como

semelhantes e nem amar como a si mesmos aqueles que o acaso separou de si por um abismo." WEIL. A llíada ou o poema da força, p. 342.
Weil ${ }^{34}$. O caminho de redenção que passa pela força não é o de admiração ou exaltação da força, mas sim, segundo Weil, é aquele que, a partir da compreensão de que a subordinação à força é universal e inevitável, leva ao reconhecimento e à aceitação de que todos partilham da mesma miséria humana Tal reconhecimento e tal aceitação são, na visão da autora, indispensáveis para que surjam a justiça e o $\operatorname{amor}^{35}$.

Pode-se pensar, de resto, que o estado de exceção - o estado de suspensão súbita de um ordenamento jurídico anteriormente estabelecido por alguma forma de pacto socia - presentifica de modo bastante significativo aquele confronto entre a materialidade caótica e a construção racional e teleológica do mundo, confronto que pauta toda a experiência humana. Nesse sentido, o estado de exceção pode ser visto como um momento privilegiado para se considerar a necessidade e também a possibilidade de alguma forma de redenção do gênero humano frente à permanente ameaça da natureza e da força. Pois o estado de exceção é, política e juridicamente falando, uma ocasião em que se abre a oportunidade para a criação de uma nova ordem, de uma nova forma de administrar o mundo. É, potencialmente, um momento fundacional. Assim, o estado de exceção não é necessariamente, embora o seja potencialmente, regido pela lei da força. Um esforço de redenção ${ }^{36}$ propiciado por essa ocasião é o de buscar que a força não seja aquilo que definitivamente se imponha.

Enquanto o personagem Klaus Klump parece sensíve à ambiguidade comportada pelo estado de exceção - uma vez que ele percebe nos sons que caracterizam a guerra uma espécie de síntese entre o humano e o animal -, há outro personagem para o qual tal ambiguidade não ocorre e que se mostra um enfático entusiasta do império da força no regime de exceção, decepcionando-se com o fim da guerra e com a volta da democracia. Trata-se do industrial Leo Vast, milionário dono de duas das cinco maiores indústrias da região, com quem Herthe, a mulher que "se entende" ${ }^{3}$ com os militares, como diz o narrador, se casa pela segunda vez. A guerra é vantajosa para os negócios de Leo Vast. Ele teme quando ela chega ao fim e, a respeito da democracia, posiciona-se do seguinte modo:

A democracia instala-se no país como uma borracha que se vai derretendo lentamente até preencher por completo a superfície de um compartimento. Mas a democracia é a instalação da cobardia mútua, e tal sistema não parte nunca de uma vontade forte, de uma intenção original; pelo contrário: é consequência de uma matéria que derreteu. Não é um sistema político de material primário. É o fogo que a faz: à democracia. É o excesso de calor, o calor já não suportável
36. Entendendo-se aqui a redenção, a partir das considerações de Simone Weil, como o estado de equidade e justiça nas relações humanas que surge a partir da percepção da vulnerabilidade universal à matéria.

37. Em troca de proteção para si para sua família, Herthe aceita com os militares de patente mais elevada. 
38. TAVARES. Um homem: Klaus Klump, p. 103.

39. ARENDT. Sobre a violência.

40. Hannah Arendt observa a existência de um "estranho consenso" na teoria política a violência: "Oumom quer quer vilecia: "Quem quer que sentido nos registros do pasma de viuse quas e griog do assado violencia como um fenîner marginal Seja Clausewitz arginal. Seja Clausewitz continuac̃o a gúrítica como a 'continuaçao da poltica por outros meios', seja Engels definindo a volencia como o acelerador do desenvolvimento econômico, a poĺtica oul sobe a conthuidade politica ou econômica, sobre a continuidade de un processo que permanece determinado por aquilo que precedeu a açấo violência (A. 23) E Sobre a violencia., p. 23.) E ainda: "Se nos voltamos para as discussōes do fenômeno do poder, rapidamente percebemos existir um consenso entre os teóricos da política, da esquerda a direita, no sentido de que a violência é tão-somente mais flagrante manifestação de poder." Grifo nosso. (ARENDT. Sobre a violência, p. 51.). Questiona-se a autora, afinal: "Sera que todos, da direita à esquerda, de Bertrand de Jouvenel a Mao Tsé-tung, deveriam concordar a respeito de um aspecto tão básico da filosofia política quanto a natureza do poder?" (ARENDT. Sobre a violência, p. 54) >>> que impõe a trégua da calma. E será depois o frio prolongado a reatar de novo a matéria principal, a Força primeira. A democracia é um efeito da perda de Força de um conjunto de homens. É um ganho de fraqueza global.

Era Leo Vast que assim pensava naquele instante. A borracha derreteu-se, murmurava ele. Derreteram a matéria forte e agora temos os pés instalados em esponja. Não sabemos o que vai acontecer. ${ }^{38}$

Interessante a associação que tanto Leo Vast (de forma direta) quanto Klaus Klump (de forma indireta) fazem entre a violência e o poder. Para Klaus os sons da guerra são sedutores porque anunciam o nascimento de uma nova forma de domínio no mundo. Ou seja, ele parece ansiar que da violência brote uma forma inédita e mais eficaz de poder. Para Leo Vast, o fim da guerra é desvantajoso porque instala uma forma mais frouxa e menos segura de poder, a democracia, que "não é um sistema político de material primário". Nota-se, desse modo, que para esses personagen a violência, especificamente a violência que se materializa na guerra, consiste numa forma de exercício do poder. A sua forma mais eficaz. O poder aqui, portanto, possu uma natureza diametralmente oposta àquela que Hannah Arendt propõe em sua inovadora análise desenvolvida no ensaio "Sobre a Violência" (On Violence) ${ }^{39}$. Contrariando a tradição majoritária do pensamento político ${ }^{40}$, que vê na

$\begin{array}{lllllll}\text { EM TESE } & \text { BELO HORIZONTE } & \text { v. } 20 & \text { N. } 2 & \text { MAIO-A60. } 2014 & \text { BORDINI. Um retrato da guerra e do estado de exceção no romance [...] } & \text { P. 68-78 }\end{array}$

violência a mais flagrante manifestação do poder, Arendt afirma tratarem-se, na verdade, de termos opostos. Quer dizer, para ela, enquanto o poder resulta da capacidade humana de agir em conjunto, em uníssono, e é inerente a toda comunidade política (sendo, portanto, não o meio para a consecução de um fim, mas "a própria condição que possibilita a um grupo de pessoas pensar e agir em termos de meios e fim" ${ }^{\prime 1}$ ), a violência, por sua vez, possui sempre um caráter instrumental, e, portanto, não pode ser legítima ou ilegítima, mas apenas justificada ou injustificável ${ }^{42}$. Desse modo, para Arendt violência e poder não apenas não são a mesma coisa como, politicamente falando, são realidades que se opõem (numa distinção que é sempre relacional ${ }^{43}$ ), na medida em que "onde um domina de forma absoluta, o outro está ausente" ${ }^{44}$

No entanto, a perspectiva que identifica poder e violência será a perspectiva adotada por todos os personagens masculinos centrais dos quatro romances de $O$ Reino. Tal visão será responsável por tornar impraticável qualquer relação interpessoal saudável que esses personagens venham a estabelecer. Essa visão é também o que está por trás da insustentabilidade democrática das instituições político-administrativas que aparecem nos romances, notadamente no último, Aprender a rezar na era da técnica.
40. >>> A tal concepção Hannah Arendt contrapõe a visão de que o poder, inerente a qualquer comunidade política, resulta da capacidade humana para agir em conjunto, o que requer $\mathrm{o}$ consenso de muitos quanto a um determinado curso de ação, de tal forma que poder e violência são termos opostos.

41. ARENDT. Sobre a violência, p. 28.

42. "Para Arendt, mais importante que a distinção tradicional entre
violência legítima e ilegítima é a distinção entre o poder legítimo distinção entre o poder legitimo o poder ilegitimo, posto que apenas o poder pode ser legítimo, ao passo que a violência pode ser DUARTE. Ensaio crítico: Poder e violência no pensamento político de Hannamento reconsideração, p. 147.

43. André Duarte considera, no ensaio citado na nota acima que o cotidiano político institucional nunca nos apresenta situações de "puro poder isento de violência", e nem de "pura violência desprovida de qualquer base efetiva de poder", no entanto, concluí invalidam a distinçâo arendtiana entre poder e violência, mas entre poder e violência, mas em sua especificidade própria, isto é, como uma distinção relacional expressa como relação de proporcionalidade". DUARTE. Ensaio crítico: Poder e violência no pensamento político de Hannah Arendt: uma reconsideração, p. 136.

44. ARENDT. Sobre a violência, p. 30. 
45. Simone Weil diz que os únicos momentos, na llíada, em que a força não joga todos na mesm vala comum são aqueles em que temos um vislumbre da alma dos guerreiros, isto é, em que é possível ver aquilo que há de cossecificam a des, como os sentimentos maspitallder de anor filal etc: "A força é o único herói. Tudo terminaria numa tíbia monotoni se não houvesse, espalhados por aqui e ali, momentos luminosos; breves momentos luminosos, breves quais os homins tem ume os quals os homens tem uma alma. i alma acorda assim, por um instante, para se perder logo depois pelo dominio da força, acorda pura e intacta, nenhum sentinento ambíguó, complicado ou turvo surge, só há lugar para llíada ou o poema da força, p. 337.
O espaço para o autoritarismo que é aberto pelo estado de exceção - e que se expressa, como vimos, no discurso contrário à democracia feito pelo personagem Leo Vast - não é, entretanto, o único tema desdobrado pelo romance a parti da figuração da guerra. Como mencionado, o caráter híbrido da guerra - realização humana ou sujeição do homem à materialidade incontrolável - aí representado oportuniza uma reflexão sobre a atividade humana em geral. A partir disso, pode-se pensar na força, bem como na instrumentalização dela, a violência, como um fenômeno que não se restringe apenas à guerra e ao estado de exceção que esta provoca, mas como um dado inseparável de toda atuação humana. Nesse sentido, há que se empreender um esforço permanente e incessante contra a desumanização que a força provoca, como alerta Simone Weil em seu ensaio a respeito da Iliada ${ }^{45}$. E, de modo concomitante, há que se ter presente que o embate (e a fusão) entre a materialidade incontrolável - e potencialmente desumanizadora - e o esforço organizador racional e teleológico da matéria é indispensável para que se criem as realidades especificamente humanas - sejam elas a guerra, a fabricação ou a arte - mas não é suficiente para que essas realidades permaneçam como tais. Para tanto há que se proteger contra a desumanização que a força, parte indissociável desse processo de embate entre o homem e a natureza, potencialmente acarreta.

\section{REFERÊNCIAS}

ARENDT, Hannah. Eichmann em Jerusalém - Um relato sobre a banalidade do mal. Tradução de José Rubens Siqueira. São Paulo: Companhia das Letras, 1999.

A Condição Humana. Tradução de Roberto Raposo 10 ed. Rio de Janeiro: Forense Universitária, 2008.

Sobre a violência. Tradução: André Duarte. Rio de Janeiro: Civilização Brasileira, 2009.

DUARTE, André. Ensaio crítico: Poder e violência no pensamento político de Hannah Arendt: uma reconsideração. In: ARENDT. H. Sobre a violência. Tradução: André Duarte. Rio de Janeiro: Civilização Brasileira, 2009, pp. 131-167.

TAVARES, Gonçalo M. Um homem: Klaus Klump, São Paulo: Companhia das Letras, 2007

Aprender a rezar na era da técnica: posição no mundo de Lenz Buchmann. São Paulo: Companhia das Letras, 2008.

WEIL, Simone. A llíada ou o poema da força. In: A condição operária e outros estudos sobre a opressão. Ecléa Bosi (org.) Tradução de Therezinha G. G. Langlada. Rio de Janeiro: Paz e Terra, 1979, pp. 319-344. 